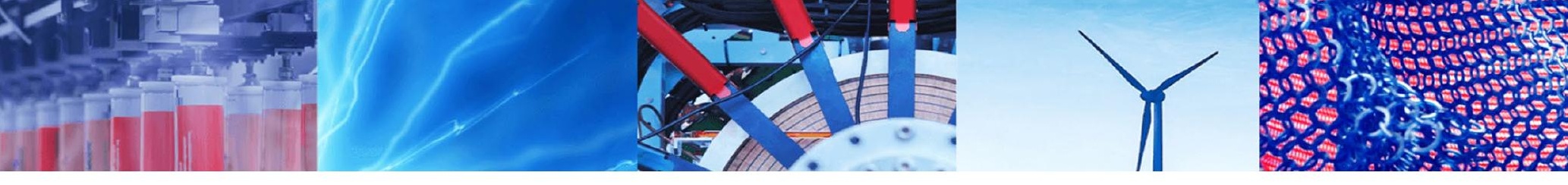

Research Article

\title{
A linear cascade tunnel for flow investigations of steam turbine rotor tip blades in subsonic nucleating flows
}

\author{
Vital Kumar Yadav Pillala ${ }^{1,4}$ - B. V. S. S. S. Prasad ${ }^{2} \cdot$ N. Sitaram² $\cdot$ M. Mahendran ${ }^{1,5} \cdot$ Debasish Biswas $^{3} \cdot$ \\ Tomohizko Jimbo ${ }^{3}$
}

Received: 11 July 2020 / Accepted: 28 January 2021 / Published online: 3 February 2021

(C) The Author(s) 2021 OPEN

\begin{abstract}
The paper presents details of a unique experimental facility along with necessary accessories and instrumentation for testing steam turbine cascade blades in wet and nucleating steam. A steam turbine rotor tip cascade is chosen for flow investigations. Cascade inlet flow measurements show uniform conditions with dry air and steam and dry air mixture of different ratios. Exit flow surveys indicate that excellent flow periodicity is obtained. Blade surface static pressure and exit total pressure distributions are also presented with dry air and with steam and dry air mixture of different ratios as the working medium at an exit Mach number of 0.52 .
\end{abstract}

Keywords Steam turbine $\cdot$ Rotor tip cascade $\cdot$ Linear cascade tunnel $\cdot$ Nucleating steam flows $\cdot$ Subsonic flow

\section{Introduction}

In spite of large importance of steam turbine testing, there are very few facilities available in the world for steam turbine testing. There are a few turbine test stands available with the steam turbine manufacturers. However these testing facilities have limited measurement capabilities. Hence understanding of the flow processes in the steam turbines is very limited. Although with the development of advanced instrumentation such as fast response miniature probe (Bosdas et al. [1]), it is possible to get detailed flow measurements behind the rotors of steam turbines (Duan et al. [2]), it is not easy to measure flow in the passages of the rotor blade. Optical methods proved helpful in obtaining detailed flow measurements in the steam turbine rotor passages. But these investigations are costly and time confusing. Modelling of flow in steam turbines is attempted by many researchers (Št'astný and Šejna [3]) but with limited success and with limited results. CFD is used to predict flow in steam turbines (Dykas et al. [4]). Extensive results are obtained, but these results have to be experimentally validated. Hence cascade testing of steam turbine blades provides useful information for understanding, modelling and improvement of flow in steam turbines. The starting point to study these problems in turbine flows satisfactorily, has been extension of the treatments of nucleating flows to two-dimensional fields. It is easy to investigate many of the problems resulting from the formation and behaviour of the liquid phase in steam turbine blading in two-dimensional cascades.

Mashmoushy et al. [5] carried out a comprehensive review on the blown-down tunnel results on steam turbine cascade tests. They concluded that the aerodynamic losses experienced by the flow are very similar under superheated and nucleating conditions in the majority of the cases. However, they found that the thermodynamic components of the losses in the nucleating tests are higher than the sum of the aerodynamic losses. They also found

$\triangle$ N. Sitaram, nsitaram.iitm@gmail.com | ${ }^{1}$ Department of Mechanical Engineering, IIT Madras, Chennai 600042 , India. ${ }^{2}$ Department of Mechanical Engineering, IIT Madras, Chennai 600036, India. ${ }^{3}$ Mechanical Systems Laboratory, Toshiba Research and Development Centre, Toshiba Corporation, Saiwai-ku, Kawasaki-shi 212-8582, Japan. ${ }^{4}$ Present Address: Department of Mechanical Engineering, Iwate University, 3-18-8 Ueda, Morioka, Iwate 020-8550, Japan. ${ }^{5}$ Present Address: Bangalore, India. 
that the flow core is free from the effects of viscous dissipation in the tests with a subsonic outlet. The drop in the total pressure allows the nucleation loss incurred by these tests to be deduced. When the cascade is tested with wet steam, the droplets present in the flow offers some surface for condensation and lowers the super cooling attained. The number and the size of the droplets and the rate of expansion determines the extent to which this is achieved. The present paper describes a subsonic cascade tunnel useful for steam turbine blading under different steam conditions. A subsonic cascade tunnel already available in Turbomachines Laboratory, Department of Mechanical Engineering of IIT Madras is modified for investigating steam turbine blades under different working conditions encountered in steam turbines (saturated, super-heated or wet steam). The modification essentially consists of adding a boiler, which supplies steam of desired condition to the tunnel. The steam is supplied through a set of nozzles and mixed with the other working fluid, air. The paper describes these details and provides preliminary measurements. The experimental facilities available in the literature are presented in Table 1. Some of the facilities are blow down tunnels with running times of a few seconds. Some of the facilities are continuously operating with steam supplied from steam power plants near the facilities. This may not be always possible. The use steam as test fluid may not be always possible. The disadvantages of using steam are high cost and complexity. While dry air can be used as test fluid [5], it is not possible to determine the effects of wetness and superheat on the steam turbine cascade performance.

A different approach is undertaken in the present investigation. Dry air is used as main test gas and steam is mixed with dry air, so that the effects of wetness and superheat can be determined. The present facility is open loop in which the back pressure varies according to atmospheric conditions. The facility can be operated continuously. The advantages of the facility are low cost and complexity. To the best of the authors' knowledge, this type of facility for testing in steam is unique.

The paper is presented as follows:

Details of the existing subsonic cascade tunnel followed by modifications made to the tunnel to work with steam air mixture as the working fluid are presented. Details of the test cascade along with the details of the instrumentation used in the present investigation are presented later. Inlet flow measurements are presented to show that the inlet flow is uniform followed by exit flow periodicity and two dimensionality results. Blade surface static pressures and exit flow measurements at four operating conditions, viz. dry air, air + steam (steam as a percentage of air: $0.86 \%$, $1.30 \%$ and $1.73 \%$ ) at an exit Mach number of 0.52 are presented. These results are discussed and conclusions drawn from the present investigation are presented at the end of the paper.

\section{Details of existing subsonic cascade tunnel}

A subsonic cascade tunnel with maximum exit Mach number of 0.52 was commissioned in Turbomachines laboratory, Department of Mechanical Engineering, IIT Madras. The details of the cascade tunnel are given in Table 2. The tunnel is described in detail in reference 15 . The working fluid in this tunnel is atmospheric air. This tunnel is upgraded to operate with steam in different conditions for studies on steam turbine blading. The details of the facility modification for testing with air and steam are given in the following sections.

Table 2 Major details of subsonic cascade tunnel

Test section: $120 \mathrm{~mm}$ height $\times 228 \mathrm{~mm}$ width (adjustable)

Maximum inlet pressure

$16,870 \pm 0.1 \% \mathrm{~Pa}$

Maximum inlet temperature

$59 \pm 1{ }^{\circ} \mathrm{C}$

Table 1 Details of steam turbine cascade tunnels

\begin{tabular}{|c|c|c|c|c|c|}
\hline S. no. & Location & Reference (s) & Tunnel size $(\mathrm{H} \times \mathrm{W})$ & Tunnel operation & Working fluid \\
\hline 1 & University of Birmingham, Birmingham, UK & Bakhtar et al. [6] & $76 \times 128 \mathrm{~mm}$ & Blow down & Steam \\
\hline 2 & Silesian University of Technology, Gliwice, Poland & Dykas et al., [7] & $110 \times 275 \mathrm{~mm}$ & Continuous & Steam \\
\hline 3 & Siemens AG KWU, Mulheim, Germany & Hosenfeld, [8] & $150 \times 300-800 \mathrm{~mm}$ & Continuous & Steam \\
\hline 4 & Moscow Power Engineering Institute, Moscow, Russia & Gribin et al. [9] & $100 \times 228 \mathrm{~mm}$ & Continuous & Steam \\
\hline 5 & University of Technology, Baghdad, Iraq & Yousif et al. [10] & $26 \times 65.4 \mathrm{~mm}$ & Continuous & Steam \\
\hline 6 & $\begin{array}{l}\text { National Power Technology and Environmental Cen- } \\
\text { tre, Leatherhead, UK }\end{array}$ & $\begin{array}{l}\text { Moore et al. [11] } \\
\text { White et al. [12] }\end{array}$ & $152 \times 320 \mathrm{~mm}$ & Continuous & Steam \\
\hline 7 & VPISU, Blacksburg, VA, USA & Song et al. [13] & $152 \times 232 \mathrm{~mm}$ & Blow down & Air \\
\hline 8 & RWTH Aachen University, Aachen, Germany & Britz et al. [14] & Annular cascade tunnel & Continuous & Air \\
\hline
\end{tabular}

SN Applied Sciences 
The inlet pressure and temperature are given for the mixed out condition at the cascade inlet.

\section{Modification of the cascade tunnel for testing in steam}

The schematic of steam turbine cascade facility is shown in Fig. 1. A boiler supplies steam at different conditions to the cascade tunnel. The steam is mixed with dry air at the desired percentage to produce the desired working fluid. The details of the boiler along with its accessories and its operation are presented below.

\subsection{Boiler}

The boiler is capable of producing $0.056 \mathrm{~kg} / \mathrm{s}$ of steam at $1000 \mathrm{kPa}$ pressure. The boiler is equipped with the superheated coil to super heat the steam up to $20-50{ }^{\circ} \mathrm{C}$. The boiler is operated through a control panel with the help of the temperature indicator to maintain the boiler temperature, hence to regularize the temperature of the steam generated. The control panel has a VFD (variable frequency drive) to control the speed of the reciprocating water pump.

The required temperature conditions of steam can be set in the control panel of the boiler, which controls the burner from injecting diesel oil. Hence the temperature of the boiler will be maintained automatically. The boiler is designed to deliver the steam at $1000 \mathrm{kPa}$ and $230^{\circ} \mathrm{C}$. The saturation temperature of steam at a pressure of $1000 \mathrm{kPa}$ is $180^{\circ} \mathrm{C}$. The required temperature of the steam can be set by the control panel of the boiler and once the steam reaches the required temperature it will be admitted into the mixing duct through the nozzles. The steam flow is measured with a flow recorder (vortex type steam flow meter manufactured by Forbes Marshal, 1 inch line size; 1 inch meter size; mass flow $=0.007$ to $0.179 \mathrm{~kg} / \mathrm{s}$ steam) mounted in the steam line.

\subsection{Boiler accessories}

The present steam supply facility line is equipped with a moisture separator, PRV (Pressure Regulating Valve), steam flow meter. The PRV is isolated by a bypass line to maintain the pressure at the downstream of the valve. The output from the boiler is fed to PRV through the moisture separator. The PRV will maintain the required downstream pressure of the steam supplied. The PRV is Forbes Marshall Model: DP23 Range of Operation: 20-1700 kPa [16].

The pressure regulating valve is a spring loaded valve which operates on the principle of spring tension. The downstream pressure condition can be set by adjusting the spring on the top of the PRV. The pressure downstream of PRV can be read by the pressure gauge of Bourdon type in the present experimental setup. Steam line from the boiler end to the inlet of the tunnel with accessories such as pressure regulating valve, flow meter etc. is shown in Fig. 2.

\subsection{Steam flow meter}

A vortex type steam flow meter manufactured by Forbes Marshal (Model: SteaMon) is installed to measure the steam flow rate of the system. The flow meter utilizes the principle of shedding of vortices from the rear of a nonstreamlined or 'bluff' body in a fluid flow. The vortices are
Fig. 1 Schematic of steam turbine cascade tunnel

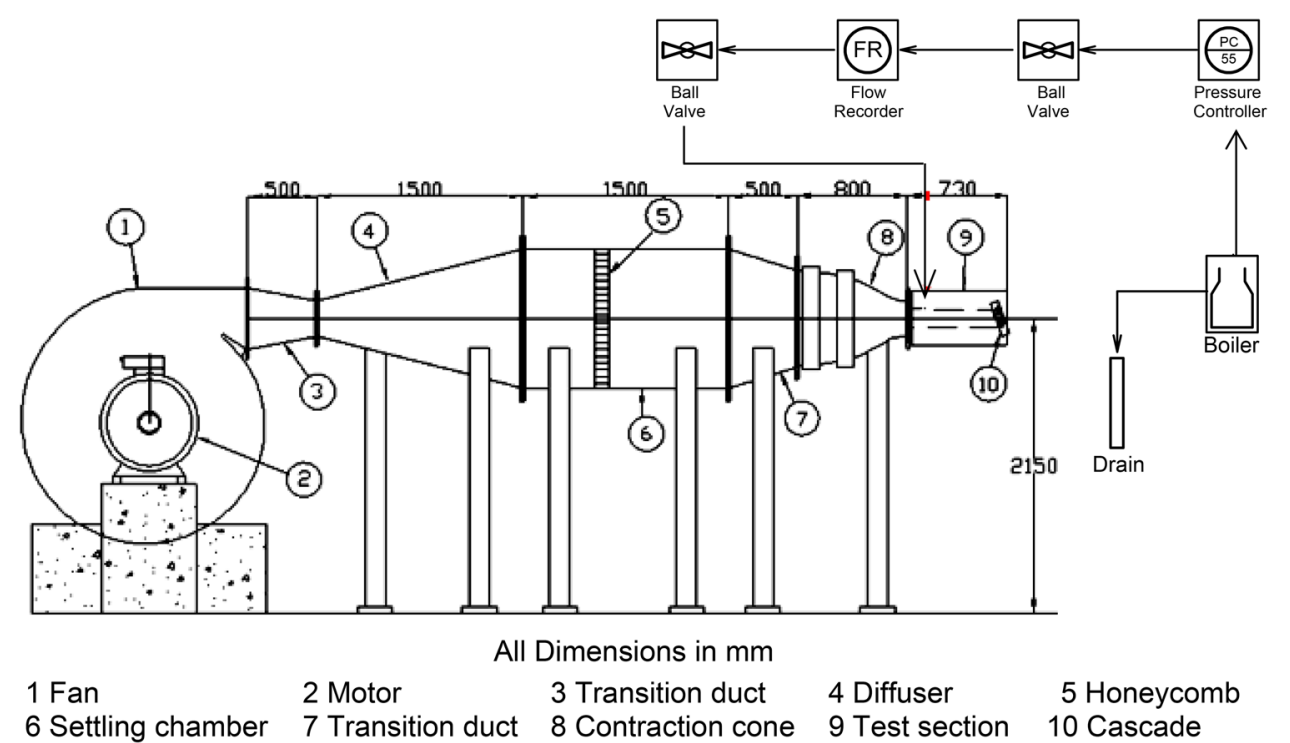


Fig. 2 Steam line with accessories

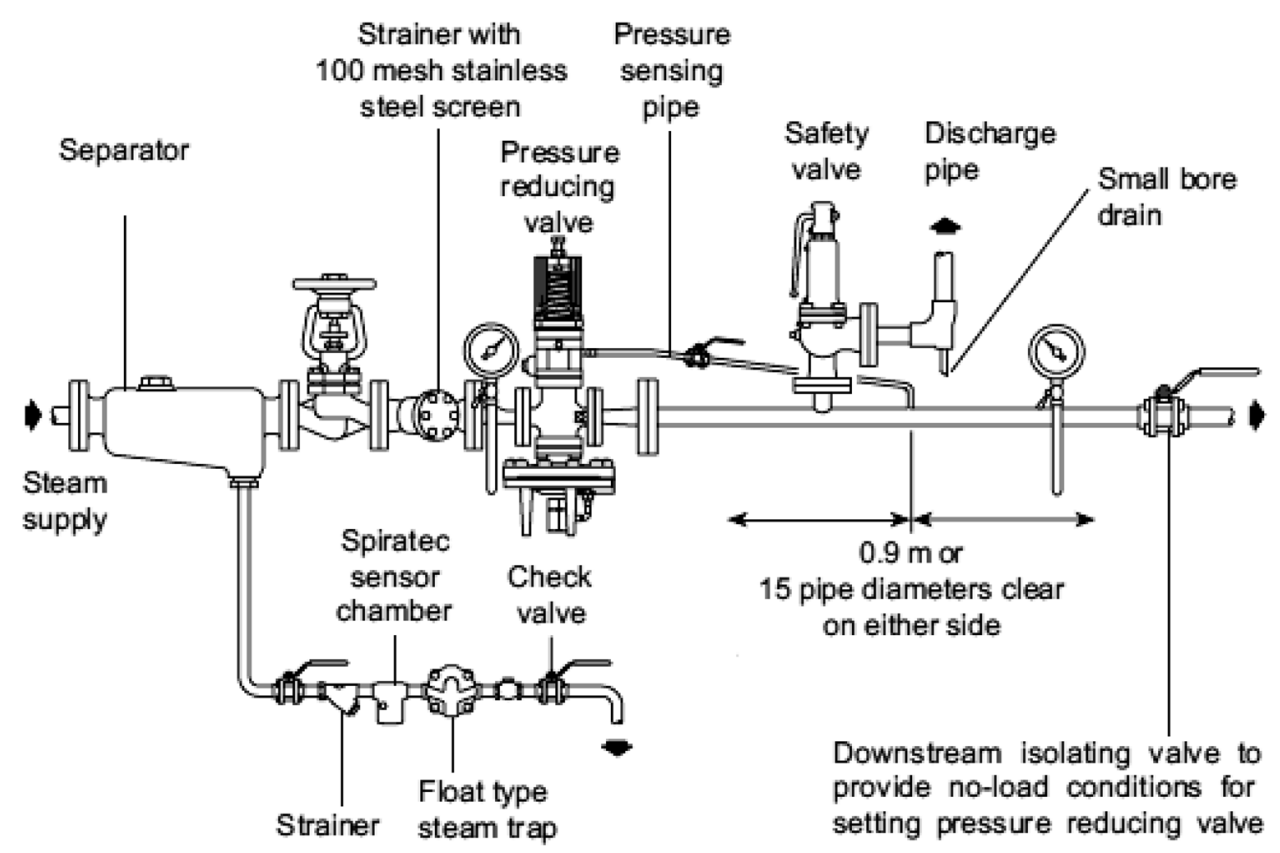

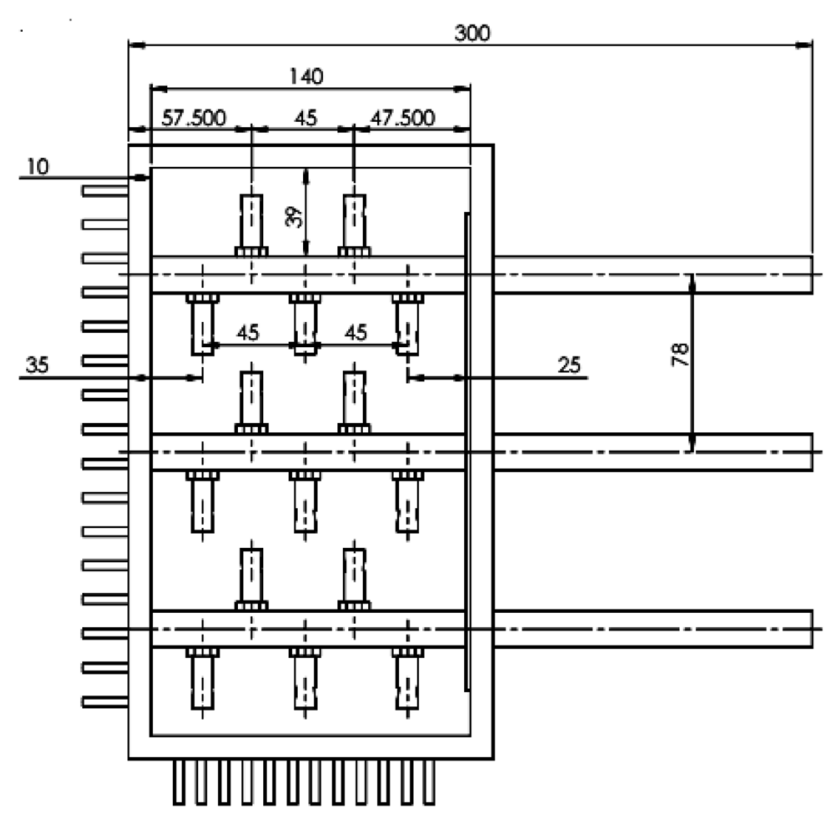

Fig. 3 Front view of nozzles connected inside the duct (all dimensions in $\mathrm{mm}$ )

detected, counted and displayed. The rate of vortex shedding is proportional to the flow rate. Hence the velocity can be measured. The limiting operating conditions for the flow meter are $210^{\circ} \mathrm{C}$ and $1750 \mathrm{kPa}$.

\subsection{Nozzles}

The steam is finally sent through the nozzle where it expands to the rig pressure. In the present setup a total
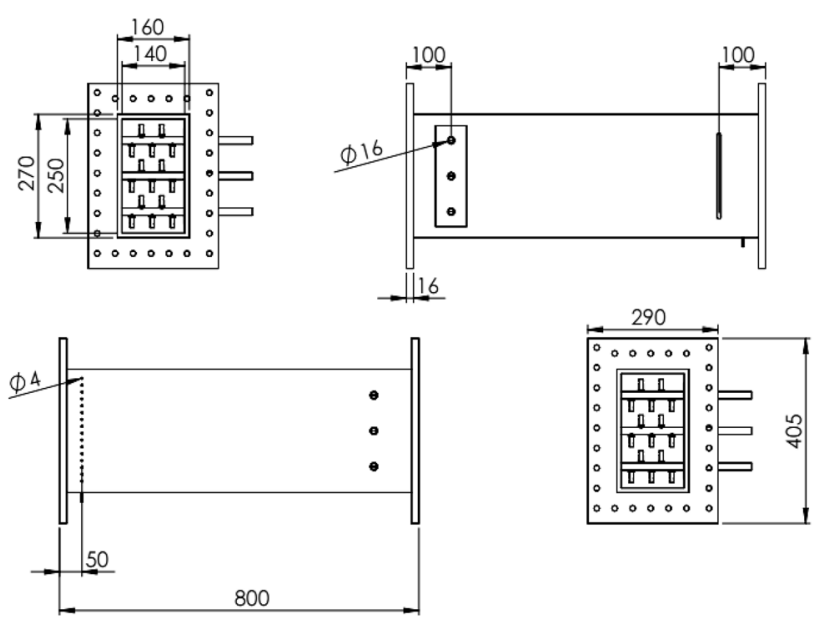

Fig. 4 Autocad drawing of mixing duct (all dimensions in $\mathrm{mm}$ )

15 number of nozzles are installed, connected to three pipes. These nozzles are fixed to each pipe as shown in Fig. 3. The female threaded part is welded to $16 \mathrm{~mm}$ outer diameter pipe by TIG (tungsten inert gas) welding. The exit of the nozzles is adjusted in such a way that the steam sprayed will be in the flow direction. Hence uniform mixing of steam with air can be ensured.

\subsection{Mixing duct}

The mixing duct connected in front of the test section is $800 \mathrm{~mm}$ in length and flow area is $250 \mathrm{~mm}$ height and $140 \mathrm{~mm}$ width. Autocad drawings of the mixing duct are shown in Fig. 4. It is fabricated with $10 \mathrm{~mm}$ thick stain steel 
sheets. The main function of the duct is to hold the spraying nozzles rigidly at one end. The length of the duct is calculated and it is found that it is sufficient to allow the steam to mix with dry air from the forced draft fan. Other end of the duct has a provision to measure static pressure. There are 17 static pressure taps in side plate and 8 static pressure taps in the bottom plate. Provision is made for mounting traverse mechanisms on the side plate and on the top plate of the duct to measure the total pressure. Figure 5 shows the arrangement of steam injection into mixing duct.

\subsection{Test cascade}

The objective of conducting cascade tests is twofold: First to generate experimental data on a turbine blade cascade typical of the last stages of steam turbine. For this purpose, "Bakhtar's blade profile" [17] is chosen. The data for this blade profile is available in open literature [17] and given in Table 3. Second, to validate the computational model to be developed during the course of present work with the experimental data that will be generated. The blade profile is generated in Solid works from the coordinates given in [17]. The blades are scaled up with a ratio of 1.39 so as to fit in the cascade tunnel of the laboratory. The blade profiles had a chord length of $60 \mathrm{~mm}$ and a span of $120 \mathrm{~mm}$ giving an aspect ratio of 2 . Hence flow two dimensionality can be established at the cascade center. The cascade consists of 7 blades and the middle three blades are instrumented to measure static pressures on the blade surfaces.

The cascade had been manufactured and installed into the existing subsonic cascade tunnel facility available at IIT Madras. As shown in Fig. 6, a total of seven blades are placed in the cascade and positioned in the cascade tunnel. The blade spacing to chord ratio is fixed at 0.8. Figure 6

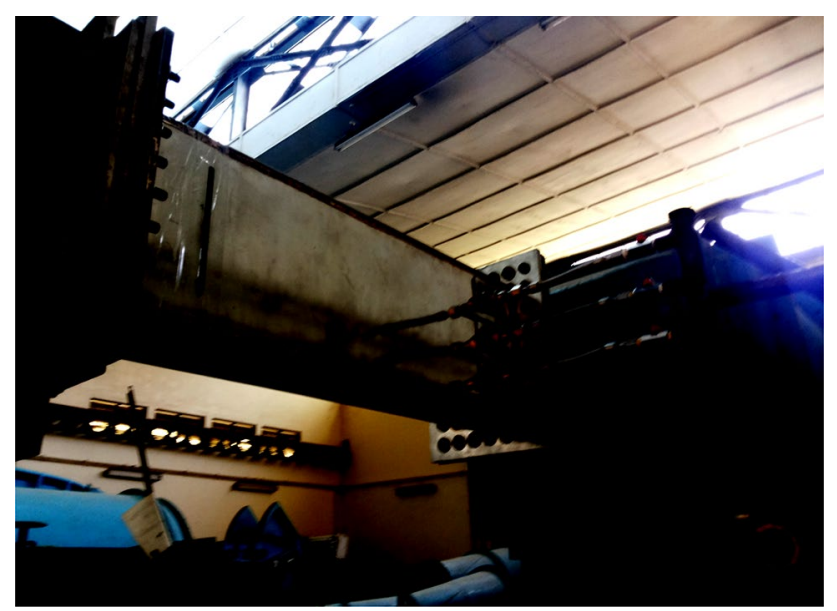

Fig. 5 Photograph showing the arrangement of steam injection into mixing duct
Table 3 Design details of cascade (steam turbine rotor tip section [17])

\begin{tabular}{llll}
\hline Chord, Ch & $60 \mathrm{~mm}$ & No. of blades & 7 \\
Spacing, S & $48 \mathrm{~mm}$ & Solidity, $\sigma=\mathrm{Ch} / \mathrm{S}$ & 1.25 \\
Span, $\mathrm{H}$ & $120 \mathrm{~mm}$ & Aspect ratio, AR $=\mathrm{H} / \mathrm{Ch}$ & 2 \\
Camber, $\theta$ & $8^{\circ}$ & Blade inlet angle, $\mathrm{a}_{1 \mathrm{~b}}$ & $52^{\circ}$ \\
Stager, $\gamma$ & $61^{\circ}$ & Blade exit angle, $\mathrm{a}_{2 \mathrm{~b}}$ & $44^{\circ}$ \\
All angles are wrt x-axis & Zweifel's coefficient, $\Psi_{\mathrm{Z}}$ & 0.68 \\
\hline
\end{tabular}

also shows adjustable plates. The purpose of these plates is to vary the test section area. A rotating disc on which the blades are mounted is also shown in the figure. The disc is to change the angle of incidence. A photograph of the cascade blades installed in the cascade tunnel is shown in Fig. 7. The blades with side plate are shown in Fig. 8.

\section{Instrumentation}

\subsection{Surface static pressure measurements}

The middle three blades have static pressure taps drilled in them. The centre blade has 17 static pressure taps on the pressure surface and the other two blades adjacent to the centre blade have 17 static pressure taps on the suction surface to verify cascade periodicity. The instrumented blades are fabricated with 17 pressure tapings on suction and pressure surfaces of the blade. The dimensions of the holes are given below:

Surface static holes: $0.5 \mathrm{~mm}$ dia. (on the suction and pressure surfaces in 3 rows).

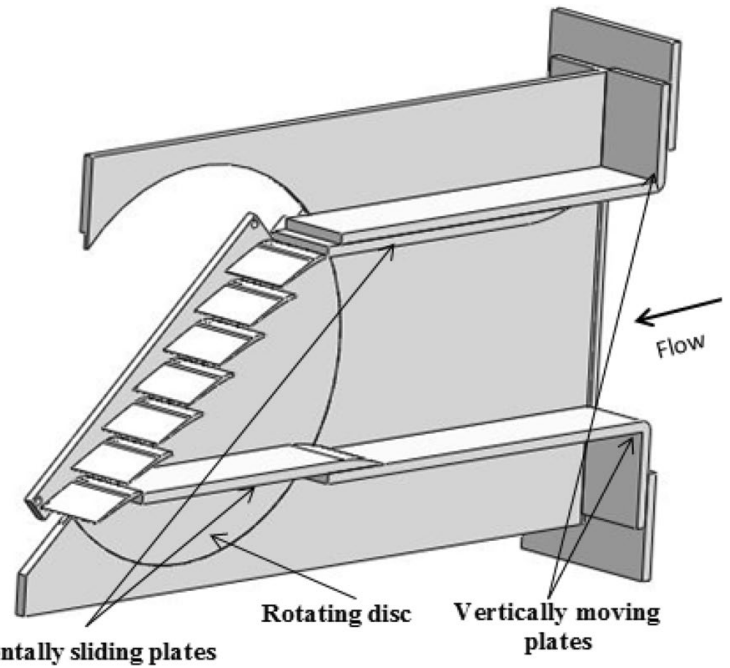

Fig. 6 Schematic of subsonic turbine blade cascade test section 


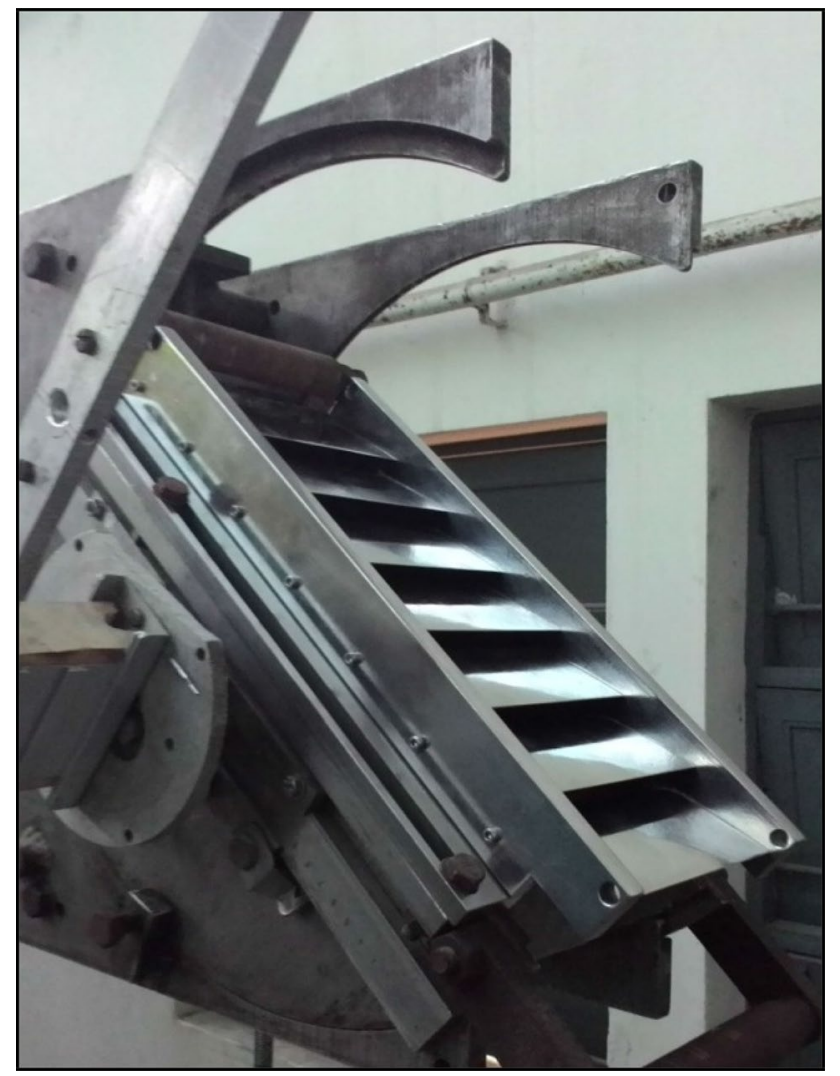

Fig. 7 Cascade installed in the tunnel

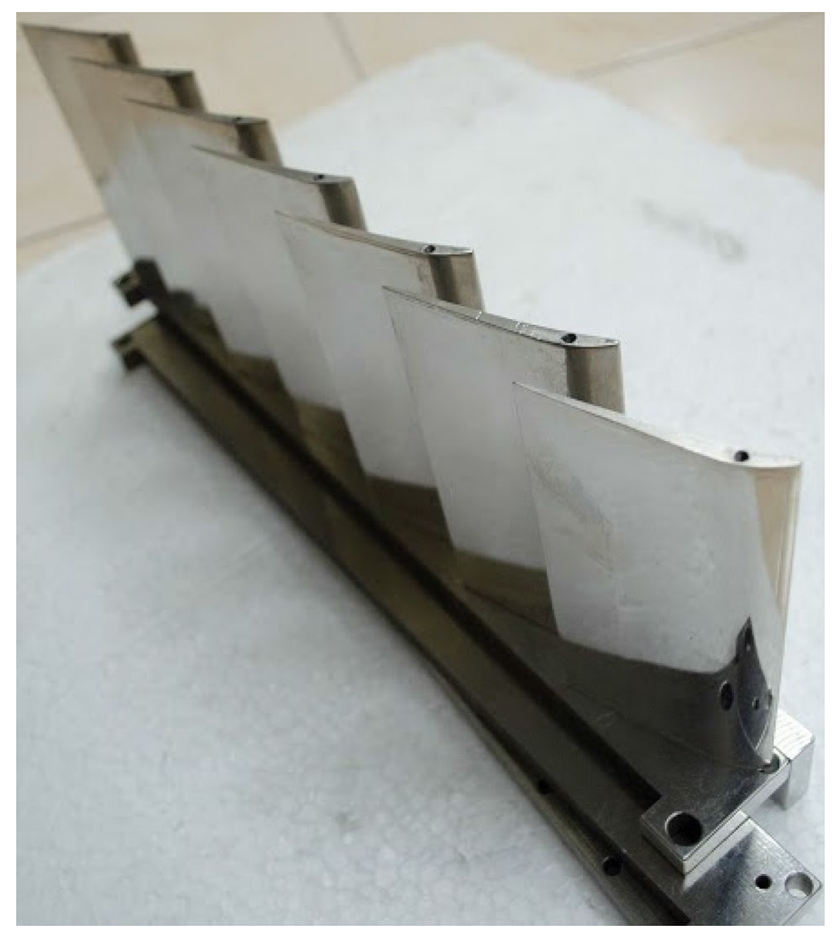

Pressure take off tubes: $0.8 \mathrm{~mm}$ dia. $(13$ holes from the leading edge) and $0.5 \mathrm{~mm}$ dia. (4 holes near trailing edge).

Each of the pressure tapping hole on the blade surfaces is connected by means of hypodermic tubes which, in turn, are joined to pressure transmitters. Figure 9 shows the blades with three rows of static pressure holes, one at the center of the blade span and the other two, $10 \mathrm{~mm}$ apart on either side of the center of the blade.

To measure the pressure, each tapping is connected to separate pressure transmitters (WIKA make, Model S20; -100 to $+60 \mathrm{kPa}$ ) with steam traps to protect the pressure transmitters from exposing to high steam temperatures as well to isolate them from condensate in the pressure line. The steam trap is filled with water or oil for this purpose. The condensate in the pressure line is removed by purging of the pressure lines. The pressure tubings are removed from the static pressure tappings and high pressure air from a reciprocating air compressor is used to purge the air + steam mixture from the tubes after each test.

\subsection{Temperature measurement}

The temperature of the working fluid (dry air + steam) is measured with a thermocouple coupled to the Pitot static tube at the inlet of the cascade. The thermocouple is J-type.

\subsection{Selection of instrumentation}

Pressure probes are extensively used to measure one, two and three dimensional aerodynamic flows. Bakhtar et al. [18] used total pressure tubes, yaw meters and static probes to measure flow in droplet, and mist and wet steam. For successful measurement of these flows, the characteristics of droplet are to be satisfactorily matched during the calibration of the instruments. Reference 19 presents the characteristics of three hole probe and static tube in superheated and wet steam.

The inlet velocity and temperature are checked for uniformity upstream the cascade at 1.5 times the axial chord with a Pitot staic tube coupled with thermocouple. The exit traversing is done using a miniature five hole probe at 1.25 times the axial chord from the cascade leading edge for the peroidity and flow angle variation. The probe is calibrated in the subsonic tunnel in the Mach number range of $0.3-0.5$ with dry air [20] in yaw and pitch angle range of $\pm 30^{\circ}$. Pressures from the pressure take off tubes of the inlet miniature Pitot probe and exit miniature five hole probe are also measured using separate pressure transmitters (WIKA make, Model S20; -100 to $+60 \mathrm{kPa}$ ) with steam trap. The purging method described in Sect. 4.1 is used to purge the air + steam mixture from the tubes after each test.

Fig. 8 Cascade of blades 
Fig. 9 Blades with static pressure taps

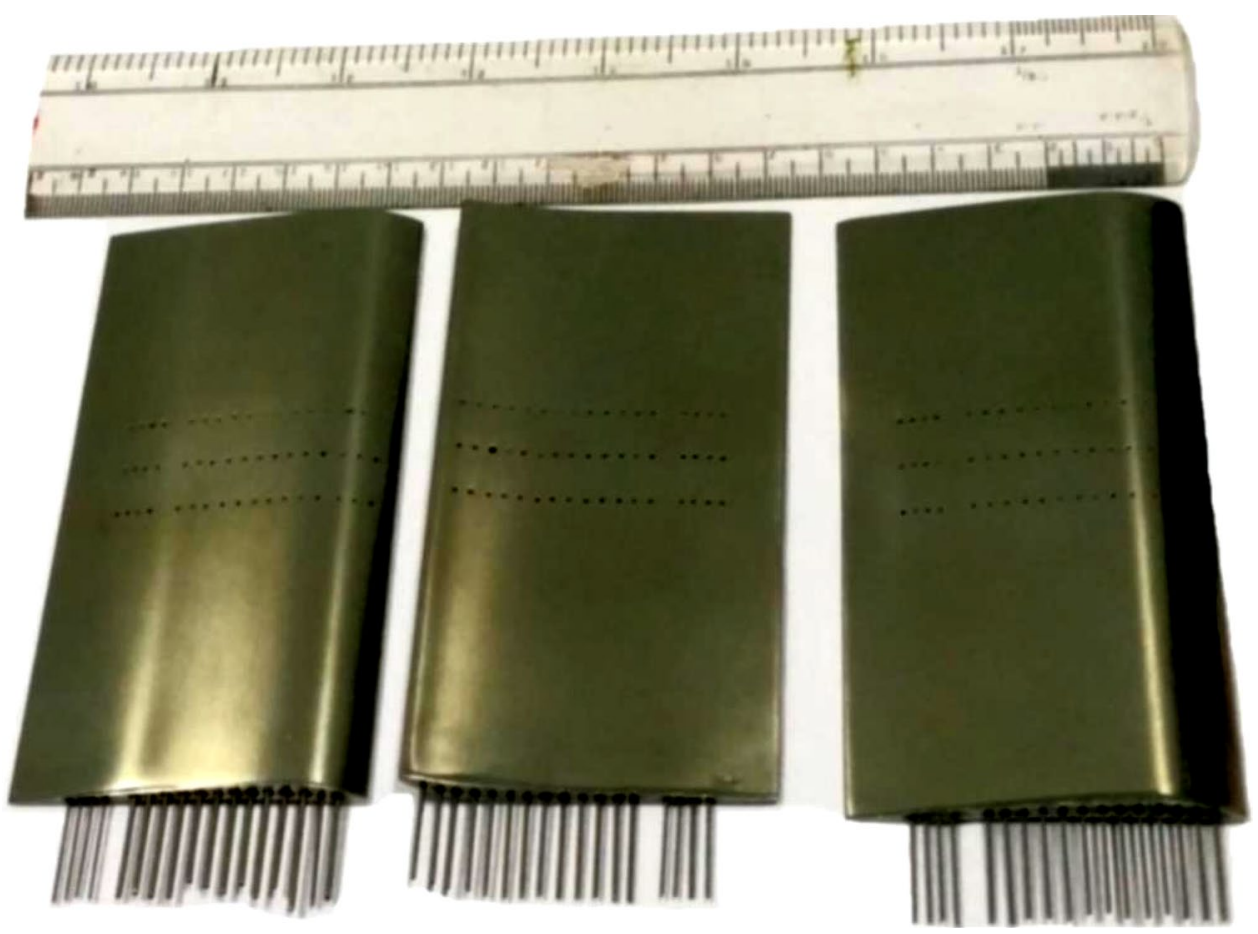

\section{Results and discussion}

\subsection{Inlet flow measurements}

The flow at the cascade inlet $(20 \mathrm{~mm}$ upstream of blade leading edge) is measured using a miniature Pitot probe at the blade midspan covering three blades. The probe is traversed at an interval of $5 \mathrm{~mm}$. Static pressure measured by the wall pressure tap is also recorded simultaneously. The measurements are carried out without and with the nozzles with dry air at a Mach number of 0.52 . The nondimensional pressures are presented in Fig. 10. Both total and static pressures are reduced when the nozzles are present. Both the inlet total and static pressures are uniform without and with nozzles.

\subsection{Exit flow periodicity measurements}

The flow at the cascade exit is measured using a miniature five hole probe to cover three blade wakes and two blade passages for three exit Mach numbers. The non-dimensional total pressures measured by the probe and Mach number derived from the probe measurements at an exit Mach number of 0.52 are presented in Fig. 11. Excellent flow periodicity is observed.

\subsection{Blade surface static pressure}

In addition measurements of the cascade exit flow are carried out at $20 \mathrm{~mm}$ above and below the mid span

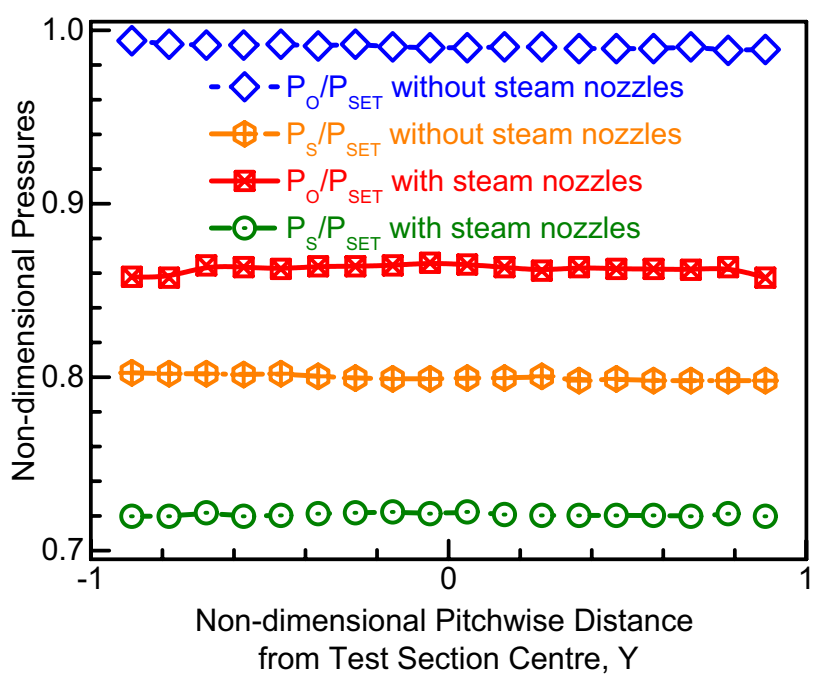

Fig. 10 Cascade inlet flow traverses at $M=0.52$

section. The flow at the three spanwise stations is found to be in good agreement confirming that the flow at the mid span is two dimensional. The static pressures on the blade surfaces at an exit Mach number of 0.52 for four flow working mediums (dry air and with steam of 0.86 , 1.30 and $1.73 \%$ of dry air) are presented in Fig. 12. The differences in the static pressures for the four working mediums seem to be very small. No direct comparison of blade surface static pressures with those of Bakhtar et al. [17] are not possible as working conditions are different. 


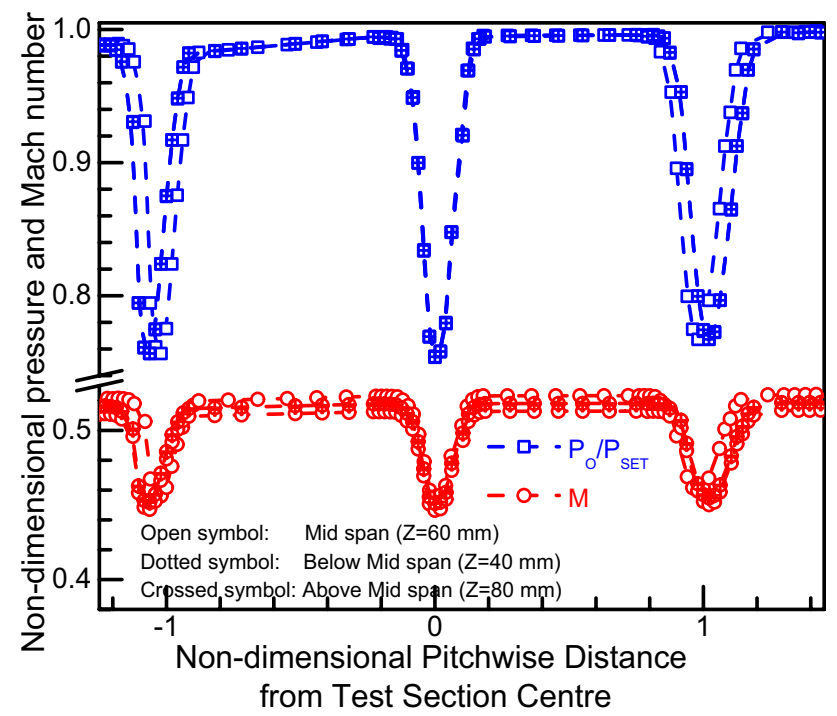

Fig. 11 Cascade exit flow traverses at $M=0.52$

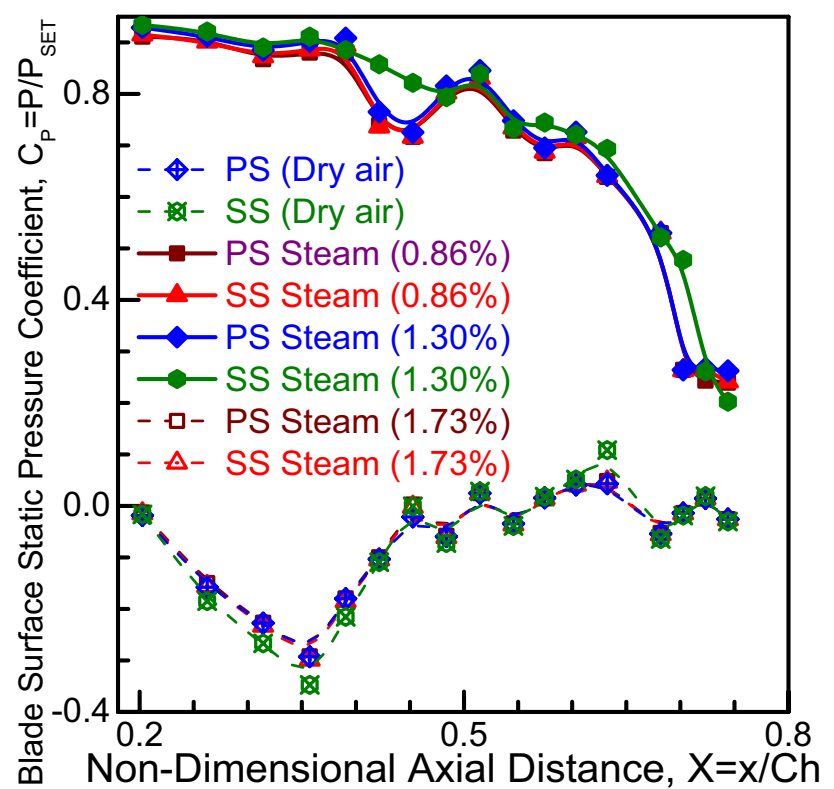

Fig. 12 Axial distribution of static pressure coefficient on blade surfaces at $M=0.52$

However the trend of blade surface static pressure distribution is very similar to that of Bakhtar et al. [17].

\subsection{Exit flow measurements}

Flow traverses at the cascade exit at an exit Mach number of 0.52 are carried out using the precalibrated five hole probe and the pitch wise distribution of total pressure coefficient for the above four flow working

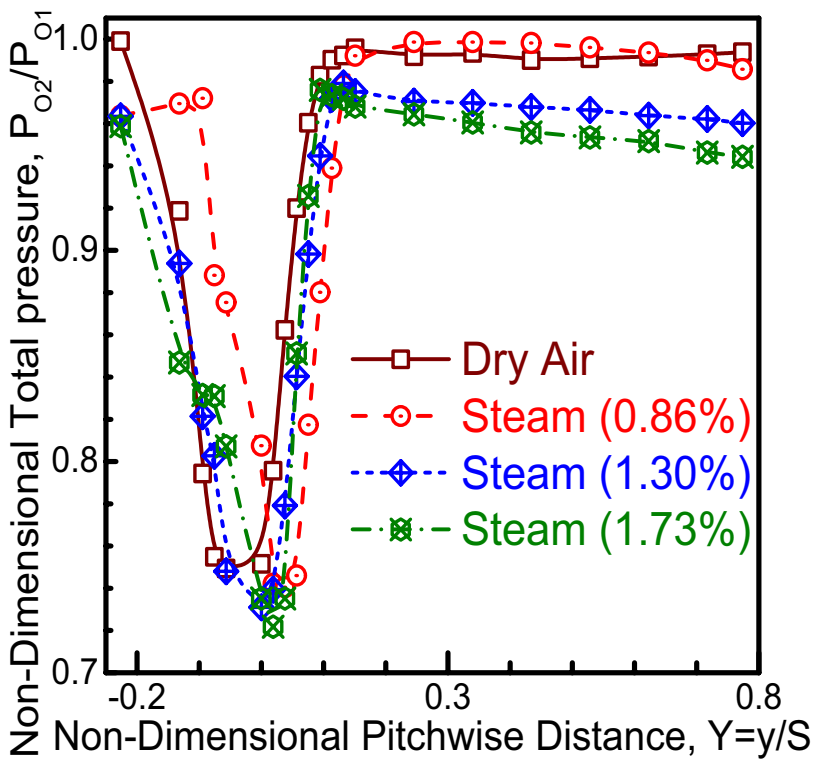

Fig. 13 Pitchwise distribution of non-dimensional total pressure at cascade exit at $\mathrm{M}=0.52$

mediums is presented in Fig. 13. With the introduction of steam, the total pressure loss increases. The cascade tunnel operating with steam air mixture did not experience any condensation in the tunnel. Wake traverses for the same cascade were available in Bakhtar et al. [21]. However no direct comparison is attempted as the operating conditions are different. However the trend of wake traverses for the three sets of experiments is similar.

\subsection{Total pressure loss coefficient}

From the total pressure distributions, total pressure loss coefficient is calculated and the pitch wise distribution of total pressure loss coefficient for the four flow working mediums at the cascade exit at an exit Mach number of 0.52 is presented in Fig. 14. The peak total pressure loss coefficient for the dry air as working flow medium occurs at slightly different pitch wise location compared to that for the steam and dry air working medium. Also its value is slightly lower than that for the steam and dry air working medium. From the pitch wise distribution of total pressure loss coefficients, its averaged value is calculated and presented in Fig. 15. From the figure, it is evident the averaged total pressure coefficient varies nearly linear with percentage of steam in dry air. However the increase in the total pressure loss coefficient with the percentage of steam is moderate, 0.075 at zero steam flow to 0.0975 (that is just about $25 \%$ or $17 \%$ per $1 \%$ steam flow) at $1.73 \%$ steam flow. 


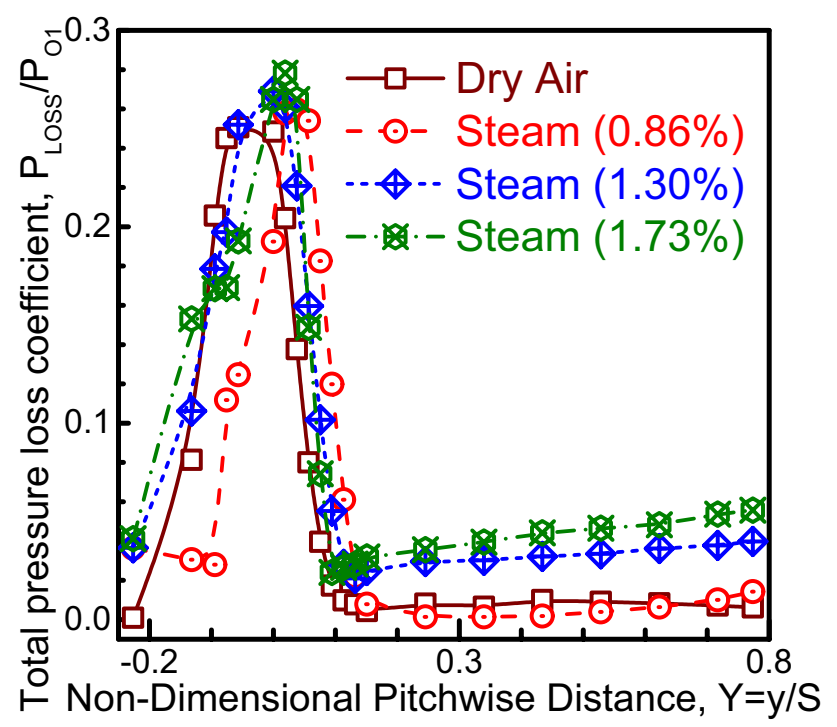

Fig. 14 Pitchwise distribution of total pressure loss coefficient at cascade exit at $\mathrm{M}=0.52$

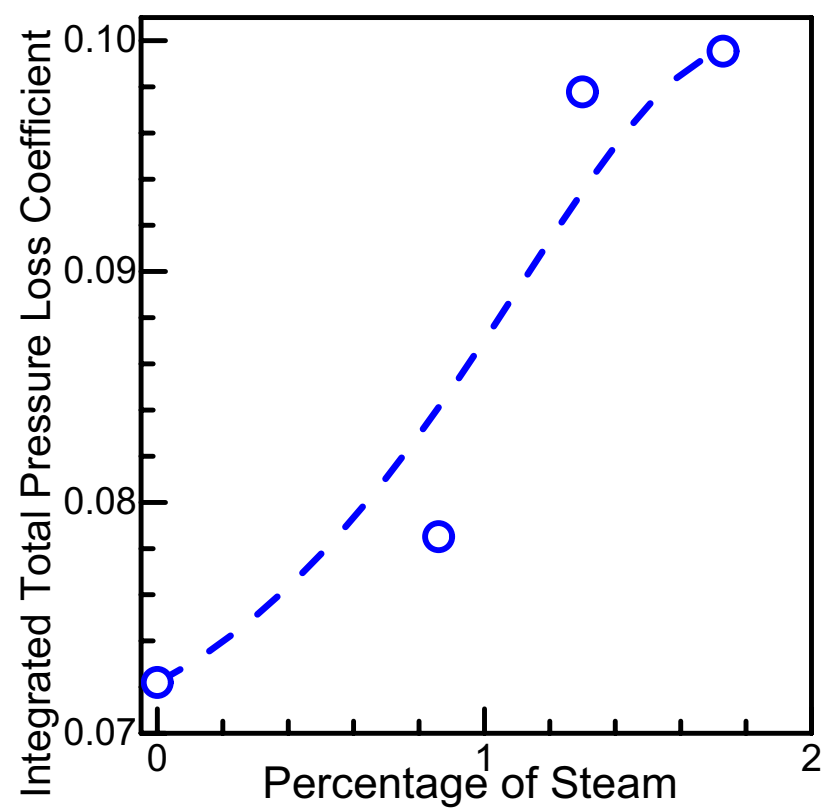

Fig. 15 Variation of total pressure loss coefficient with percentage of steam at $M=0.52$

\section{Conclusions}

The existing subsonic tunnel is modified to accommodate the steam generation facility to test the steam turbine cascade blading with steam at different steam conditions as working medium. The subsonic tunnel is open loop continuous operation tunnel. The back pressure of the tunnel varies accordingly with the atmospheric conditions. The steam conditions can be changed by varying the pressure and the inlet temperature. This facility is of unique nature as the working fluid is air and steam mixture instead steam only. Hence the facility cost and complexity are low. To the best of our knowledge, this type of facility for testing in steam is unique.

Results are presented for a steam turbine rotor tip cascade with dry air and with steam mixed with dry air as the working medium at an exit Mach number 0.52. These results include static pressure distribution on the blade suction and pressure surfaces and wake traverses at the blade exit. The averaged total pressure loss coefficient varies nearly linear with the percentage of steam in dry air. The increase in the total pressure loss coefficient with the percentage of steam is moderate, 0.075 at zero steam flow to 0.0975 (that is just about $25 \%$ or $17 \%$ per $1 \%$ steam flow) at $1.73 \%$ steam flow. The results are consistent and comparable with the results available in the open literature for the cascade.

Acknowledgements The help of Mr. Joby Joseph and Mr. Vigney Kumar in designing the nozzle is gratefully acknowledged. M/s J. P. Energy Systems manufactured and commissioned the boiler. The authors would like to acknowledge the help of Mr. M. Veeraghavan, Turbomachines Laboratory, Department of Mechanical Engineering, IIT Madras during commissioning of the facility and conduct of experiments. This work was presented in part at The 13th Asian International Conference on Fluid Machinery, September 7-10, 2015, Tokyo, Japan.

Funding Financial support by Toshiba Research and Development Center of Toshiba Corporation (RB1314MEE018TOSA-BVSS) is gratefully acknowledged.

\section{Compliance with ethical standards}

Conflict of interest The authors declare that there is no conflict of interest in publishing this paper.

Open Access This article is licensed under a Creative Commons Attribution 4.0 International License, which permits use, sharing, adaptation, distribution and reproduction in any medium or format, as long as you give appropriate credit to the original author(s) and the source, provide a link to the Creative Commons licence, and indicate if changes were made. The images or other third party material in this article are included in the article's Creative Commons licence, unless indicated otherwise in a credit line to the material. If material is not included in the article's Creative Commons licence and your intended use is not permitted by statutory regulation or exceeds the permitted use, you will need to obtain permission directly from the copyright holder. To view a copy of this licence, visit http://creativecommons .org/licenses/by/4.0/.

\section{References}

1. Ilias B, Michel M, Anestis K, Abhari RS (2016) A fast response miniature probe for wet steam flow field measurements. Meas 
Sci and Tech 27(12):125901. https://doi.org/10.1088/09570233/27/12/125901

2. Chongfei D, Koji I, Shigeki S, llias B, Michel M, Kalfas Al, Abhari RS (2016) Unsteady wet steam flow measurements in a lowpressure test steam turbine. Int J Fluid Mach Syst 9(1):85-94. https://doi.org/10.5293/IJFMS.2016.9.1.085

3. Št'astný $M$, Šejna $M$ (2015) Thermodynamic losses of hetero and homogeneous condensation in steam turbine cascades. Proc. Inst. Mech. Eng Part A J Power Energy 229(1):33-43. https://doi. org/10.1177/0957650914552816

4. Dykas S, Majkut M, Smołka K, Strozik M (2017) Analysis of the steam condensing flow in a linear blade cascade, presented at Wet Steam Conference, Prague, 12-14 September 2016. Proc Inst Mech Eng Part A J Power Energy 232(5):501-514. https:// doi.org/10.1177/0957650917743365

5. Mashmoushy H, Mahpeykar MR, Bakhtar F (2004) Studies of nucleating and wet steam flows in two-dimensional cascades. Proc Inst Mech Eng Part C Jl Mech Eng Sci 218:843-858. https:// doi.org/10.1243/0954406041474219

6. Bakhtar F, Webb RA, Shojaee-Fard MH, Siraj MA (1991) An experimental facility for studies of nucleating and steam flows in turbine blading. In: Proceedings of institution of mechanical engineers conferences on turbomachinery: latest developments in a changing scene, conference publications, paper C423/003, pp 191-199

7. Dykas S, Majkut M, Strozik M, Smołka K (2015) Experimental study of condensing steam flow in nozzles and linear blade cascade. Int J Heat Mass Transf 80:50-57. https://doi.org/10.1016/j. ijheatmasstransfer.2014.09.010

8. Hosenfeld HG (1988) The steam test rig at KWU and its cascade steam tunnel. In: Symposium on measuring techniques in transonic and supersonic flows, March 11-12, Oxford, UK

9. Gribin V, Tishchenko A, Gavrilov I, Tishchenko V, Khomyakov S, Popov V (2014) Experimental studies of supersonic steam flow in the flat nozzle blade cascade at different initial steam conditions. In: Proceeding of ASME turbo expo 2014: turbine technical conferences and expo. GT2014, June 16-20, Düsseldorf, Germany, GT2014-26209, V01BT27A034; 7 p. https://doi. org/10.1115/GT2014-26209

10. Yousif AH, Al-Dabbagh AM, Mahawi Reyadh Ch (2013) Effect of exit pressure of steam turbine last stage cascade blade on two phases of saturated vapor and water droplet. Eng Tech J 31(2):235-253

11. Moore MJ, Walters PT, Crane RI, Davidson BJ (1973) Predicting fog size in wet steam turbines. In: Institution of mechanical engineers conferences wet steam 4. University of Warwick, C37/73

12. White AJ, Young JB, Walters PT (1996) Experimental validation of condensing flow theory for a stationary cascade of steam turbine blades. Philos Trans Math Phys Eng Sci 354(1704):59-88. https://doi.org/10.1098/rsta.1996.0003

13. Song B, Ng WF, Cotroneo JA, Hofer DC, Siden G (2007) Aerodynamic design and testing of three low solidity steam turbine nozzle cascades. Trans ASME J Turbo 129(1):62-71. https://doi. org/10.1115/1.2372774

14. Britz M, Jeschke P, Brunn O, Polklas T (2017) The use of airmeasured profile data for application in a high pressure steam turbine. In: Proceedings ASME GT2017, volume 8: microturbines, turbochargers and small turbomachines; steam turbines, V008T29A020, June 26-30, Charlotte, NC, USA. https:// doi.org/10.1115/GT2017-63667

15. Mahendran M, Sitaram N, Jain GK, Pramod E (2008) Design and commissioning of a subsonic cascade tunnel with automatic data acquisition capabilities. In: International conferences on aerospace science and technology, paper no. 2008-P005, Poster session, June 26-28, Bangalore, India

16. Forbes M. S. G. iron pressure reducing valves DP23 installation and maintenance instructions, Spirax Marshall Limited (A Forbes Marshall Company)

17. Bakhtar F, Ebrahimi M, Webb RA (1995) On the performance of a cascade of turbine rotor tip section blading in nucleating steam, part 1: surface pressure distributions. Proc Inst Mech Eng Part C J Mech Eng Sci 209:115-124. https://doi.org/10.1243/ PIME_PROC_1995_209_131_02

18. Bakhtar F, Mashmoshy H, Jadayel OC (2001) Calibration characteristics of a three hole probe and static tube in wet steam. Int J Heat Fluid Flow 22:537-542. https://doi.org/10.1016/S0142 $-727 \times(01) 00111-4$

19. Kleitz A, Dorey JM (2004) Instrumentation for wet steam. Proc Inst Mech Eng Part C J Mech Eng Sci 218:811-832. https://doi. org/10.1243/0954406041474192

20. Sitaram N, Pillala VKY, Purushothama B, Prasad BVSSS (2015) Calibration of multi hole pressure probes for three dimensional flow measurements at high Mach numbers. In: Proceedings of the 12th international symposium on experimental and computational aerothermodynamics of internal flows, July 13-16, 2015 Lerici, Italy, Paper No. ISAIF 111, 1-9

21. Bakhtar F, Ebrahimi M, Webb RA (1994) An investigation of nucleating flows of stream in a cascade of turbine bladingwake traverses. Trans ASME J Fluids Eng 116(1):121-127. https ://doi.org/10.1115/1.2910219

Publisher's Note Springer Nature remains neutral with regard to jurisdictional claims in published maps and institutional affiliations. 